\title{
Gross Morphometrical Studies on Pectoral Girdle of Pariah Kite (Milvus migrans)
}

\author{
${ }^{1}$ M.P.S. Tomar, ${ }^{1}$ Rakhi Vaish, ${ }^{2}$ Nidhi Rajput and ${ }^{2}$ A.B. Shrivastav \\ ${ }^{1}$ Department of Veterinary Anatomy and Histology, \\ ${ }^{2} \mathrm{Center}$ for Wildlife Forensic and Health \\ College of Veterinary Science and Animal Husbandry, \\ Jabalpur-482001 (M.P.), India
}

\begin{abstract}
Pectoral girdle of an adult Pariah kite (Milvus migrans) was studied, procured from Department of Wildlife Health and Management, Jabalpur. The girdle was composed of 3 bones viz. scapula, coracoid and clavicle. The scapula was sword shaped. The length and maximum width of scapula were 5.40 and $1.00 \mathrm{~cm}$, respectively. The clavicle was in the form of thick, curved plate. It was directed forwards, downwards and inwards to join the bone of opposite side by forming the curved $U$ shaped furculum. The width of clavicle gradually decreased from proximal to distal end. Hypocleideum was not prominent at their meeting point. The length and maximum width were 5.80 and $1.30 \mathrm{~cm}$, respectively. Distance between ventral end of clavicle and anterior extremity of sternum was $1.00 \mathrm{~cm}$. Coracoid was directed downwards and backwards to articulate the sternum distally. Proximal extremity was hook like. Length and maximum width were 3.40 and $2.50 \mathrm{~cm}$ (at sternal end), respectively. Proximal extremity of scapula, coracoid and clavicle united to form foramen triosseum. The diameter of foramen triosseum was $0.30 \mathrm{~cm}$.
\end{abstract}

Key words: Morphometry, scapula, coracoid, clavicle, pariah kite, foramen triosseum

\section{INTRODUCTION}

Detailed information are available on various bones of domestic fowl (Bradley and Grahame, 1960; Getty, 1975; King and McLelland, 1975). Some literature are available on wild birds viz. Emu (Shankhpal et al., 2006) and Indian crow (Patki et al., 2010) however, very meager information is available on morphometrical studies on Pariah kite. Keeping these facts in view, the present study was undertaken to identify the species on the basis of bones of Pariah kite.

\section{MATERIALS AND METHODS}

The carcass was procured from Department of Wildlife Health and Management, Veterinary College Jabalpur (M.P.) India. After procurement of carcass the skeleton was taken out by maceration method. The morphological and morphometrical studies were conducted on pectoral girdle.

\section{RESULTS AND DISCUSSION}

The pectoral girdle in Pariah kite is composed of three bones viz. Scapula, clavicle and furculum as in

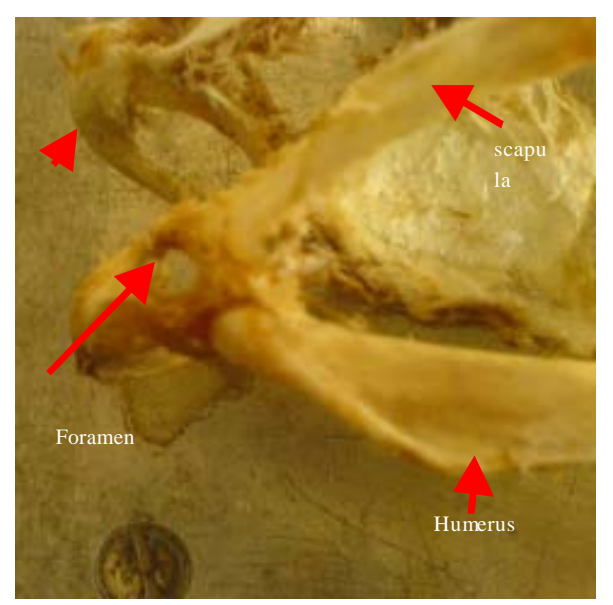

Fig. 1: Articulation with limbs and sternum

fowl (Bradley and Grahame, 1960; Getty, 1975; King and McLelland, 1975) (Fig. 1 and 2).

Scapula: The scapula was sword shaped but much smaller in relation to body size. Scapula was composed of proximal extremity and blade. It was directed backwards and upwards. The proximal end was composed of lateral articular facet and medial pointed process separated by a

Corresponding Author: M.P.S. Tomar, Department of Veterinary Anatomy and Histology, College of Veterinary Science, Jabalpur, India 


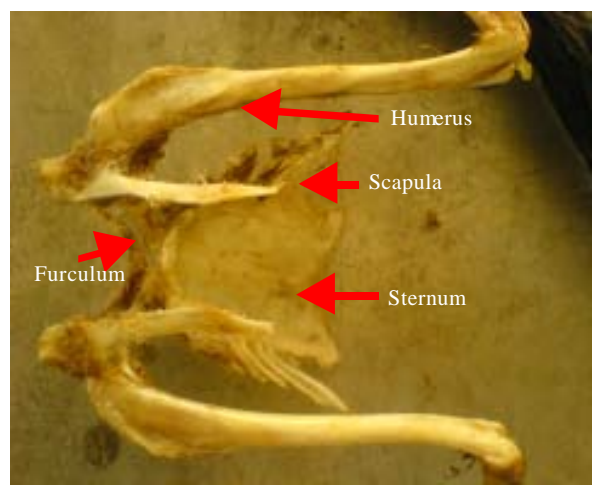

Fig. 2: Articulation with limbs and sternum

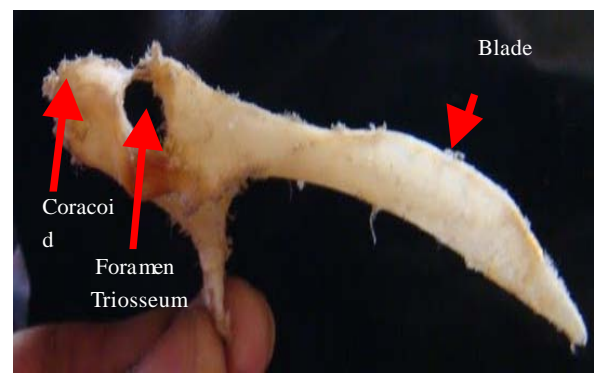

Fig. 3: Scapula

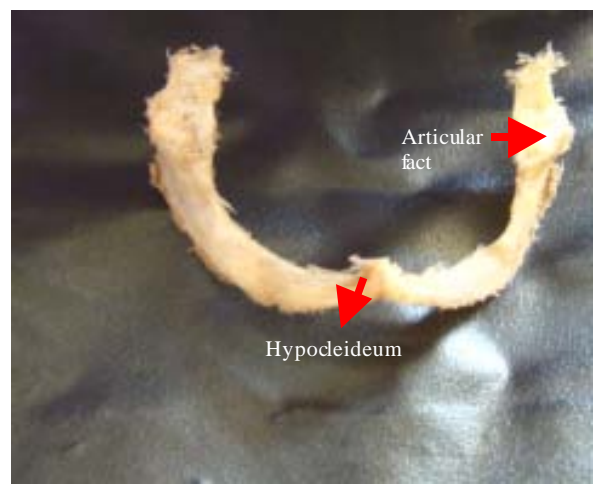

Fig. 4: Furculum

shallow, curved notch. Lateral facet articulated with the head of humerus and formed shoulder joint. Medial pointed end articulated with cranial end of clavicle. Medial pointed end ventrally articulated with the coracoid bone to form foramen triosseum. Similar findings were reported in fowl except the larger size of bone in comparison to body size (Getty, 1975). The blade was narrow and flattened dorso-ventrally in it's cranial 1.5 th part and wider and flattened medio-laterally in remaining part. Caudally blade ended in the form of pointed projection which was directed downwards and curved inwards. Middle part of blade was strongly convex dorsally and straight ventrally (Fig. 3).

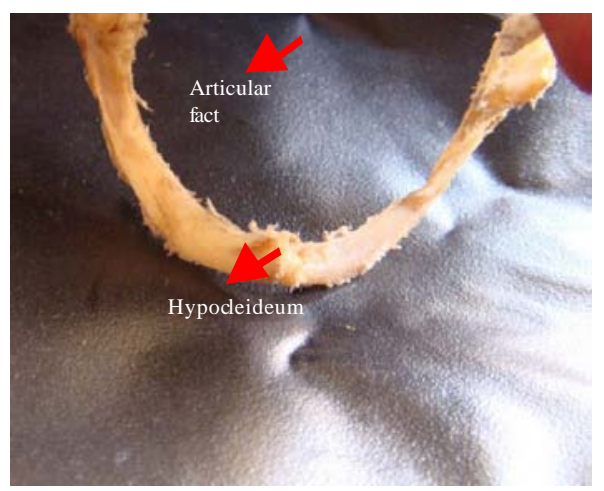

Fig. 5: Furculum

\section{Measurements:}

- Distance between two scapulae

- At the level of foramen triosseum $\quad=3.10 \mathrm{~cm}$

- At the level of mid of scapular blade $\quad=2.80 \mathrm{~cm}$

- At the level of posterior end of scapula $=3.90 \mathrm{~cm}$

- Length of scapula $\quad=5.40 \mathrm{~cm}$

- Maximum width of blade $\quad=1.00 \mathrm{~cm}$

Clavicles: Proximal extremity was thicker and much larger than distal extremity. This extremity was articulated with scapula and coracoid to form foramen triosseum. Distal extremity was narrow and fused with the opposite bone to form hypocleideum which was not prominent where as in crow it is in form of flattened S shaped sagietal plate (Patki et al., 2010). The ramus of furculum was flattened mediolaterally. The dorsal border was curved and concave. Ventral border was strongly convex. The furculum formed by two clavicle bones was wide and curved $U$ shaped similar observations were recorded in goose (Getty, 1975) and crow (Patki et al., 2010) (Fig. 4 and 5).

\section{Measurements:}

- Curvature length

$$
=5.80 \mathrm{~cm}
$$

- Width of bone:

- At proximal end $=1.30 \mathrm{~cm}$

- At mid point

$=0.80 \mathrm{~cm}$

- At the level of hypocleideum $=0.50 \mathrm{~cm}$

- Distance between proximal $\quad=4.20 \mathrm{~cm}$ ends of clavicle

- Distance between hypocleideum $=1.00 \mathrm{~cm}$ and sternum

Coracoid: The coracoid was long and directed downwards and backwards. The proximal end was hook like and articulated with scapula and clavicle to form 


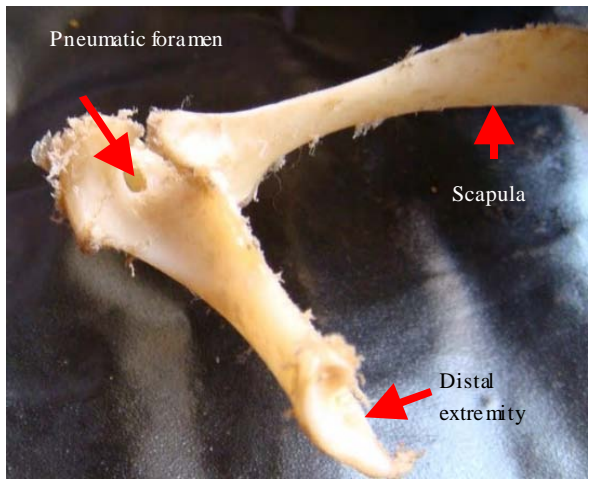

Fig. 6: Coracoid and scapula

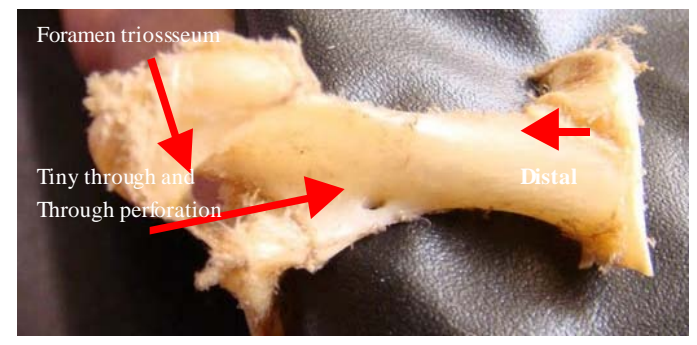

Fig. 7: Coracoid

foramen triosseum. Distally it articulated with articular facet on either side of cranial border of sternum. Pneumatic foramen was present just medial to foramen triosseum (Fig. 6). One tiny through and through perforation was present on proximal 1.3rd part of postero-medial border of bone below the foramen triosseum (Fig. 7) where as such perforations were not seen in fowl (Bradley and Grahame, 1960; Getty, 1975; King and McLelland, 1975). Width of the distal extremity is about twice to that of proximal extremity.

\section{Measurements:}

- Length

$=3.40 \mathrm{~cm}$

- Width:
- At proximal end $\quad=1.20 \mathrm{~cm}$

- At distal end $=2.50 \mathrm{~cm}$

- Distance between coracoid $=1.50 \mathrm{~cm}$ and furculum

- Diameter of foramen triosseum $=0.80 \mathrm{~cm}$

\section{CONCLUSION}

By present study, we found that pectoral girdle of Pariah Kite can be identified easily by observing the curved $U$ shaped furculum and rudimentary hypocleideum.

\section{REFERENCES}

Bradley, O.C. and T. Grahame, 1960. The Structure of the Fowl. 4th Edn., Publishers Oliver and Boyd, Edinburgh, London, pp: 5-20.

Getty, R., 1975. Sisson and Grossman's the Anatomy of Domestic Animals. 5th Edn., W.B. Saunders Co., Philadelphia, pp: 1790-1801.

King, A.S. and J. McLelland, 1975. Outlines of Avian Anatomy. Bailliere Tindall, London, pp: 15-29.

Patki, H.S., K.M. Lucy, S. Maya, K.R. Harshan and J.J. Chungath, 2010. Gross and radiographic anatomy of scapula of Indian crow. Proceedings of the 10th Indian Veterinary Congress and 17th Annual Conference of IAAVR on Newer Challenges in Veterinary Research Education.

Shankhpal, V.D., V.R. Bhamburkar, R.S. Dalvi, O.N. Ladukar and S.B. Banubakode, 2006. Osteometrical study on various bones of Emu (Dramaius novehollandiae). Proceedings of the 20th Annual Convention of IAVA and National Symposium on Recent Advances in Veterinary Anatomy and their Applications to Improve Livestock Health, Production and Reproduction. 